\title{
El desarrollo del componente estratégico dentro del marco actual de la didáctica de ELE: estado de la cuestión y perspectivas ${ }^{1}$
}

\author{
Graciela Vázquez \\ Freie Universität Berlin \\ Graciela.Vazquez@fu-berlin.de
}

Resumen: El siguiente artículo se ubica en el campo de la Lingüística Aplicada, concretamente en el área de la Metodología de E/LE y el acento está puesto en la importancia de las estrategias de aprendizaje para el desarrollo de la autonomía. En primer lugar, se revisa la bibliografía existente en cuanto a la terminología y las variables para concentrase después en la discusión de los aspectos positivos que la introducción explícita de las estrategias en los manuales ha provocado en las últimas décadas. El objetivo de esta publicación consiste en reflexionar sobre la inserción de las estrategias en el currículo, es más, aboga por un modelo donde las estrategias constituyen una bisagra entre la intervención docente y la autonomía del estudiantado. Asimismo se proporcionan ejemplos de manuales que han incorporado las estrategias como parte del proceso de aprendizaje. Se concluye haciendo alusión a aquellas áreas donde las estrategias podrían cumplir una función de apoyo considerable: la enseñanza de lenguas a inmigrantes y en el marco del aprendizaje plurilingüe.

Palabras clave: Estrategia; Técnicas; Autonomía; Evaluación; Destrezas; Competencia; Resultados de aprendizaje; Aprender a aprender.

Abstract: This article builds on previous discussions of language learning strategies in four ways: revising and/or updating seminal English-language publi-

1. Este artículo recoge ideas y partes de otras publicaciones que hasta el presente no aparecen en actas de congresos y jornadas. 
cations in the field; discussing relevant terminological problems; taking into consideration learners' variables; arguing for the explicit introduction of learning strategies in E/LE text books. My overall aim consists in demonstrating that the explicit introduction of learning strategies can ameliorate the learning process and motivate learners to be more self-directed and self-monitoring by means of self-assessment. A range of examples are provided through which I expect to make clear how theoretical principles can work in practice. I suggest that the efficient use of such strategies impacts on learning ability and can help migrants and potential multilingual learners to develop communicative skills and competencies in a more efficient way

Keywordsः Strategy; Techniques; Autonomy; Assessment; Skills; Competence; Learning outcomes; Learning to learn. 


\section{Introducción}

Voy a comenzar este artículo situando el tema objeto de estudio en lo que considero constituye el marco actual de la Didáctica de E/LE en el país donde trabajo y que guarda o debería guardar paralelismos importantes con lo que se entiende, en la práctica cotidiana y la teoría que la sustenta, el estado actual de la enseñanza y aprendizaje del castellano como lengua extranjera. El tema de las estrategias no es nuevo en la didáctica general, ni en particular en la de las lenguas extranjeras. En este último campo la investigación (en el ámbito anglosajón) ya cubre casi cuatro décadas. Tampoco lo es en la experiencia cotidiana, donde el día a día nos enfrenta a resolver problemas conocidos y desconocidos. Consciente o inconscientemente, todas las personas echamos manos de estrategias en general o en particular, para comunicarnos y resolver desafíos de aprendizaje.

El Marco Común Europeo de Referencia, el Marco para los Enfoques Plurales de las Lenguas y las Culturas (MAREP), el proceso de Bolonia, la modularización de los estudios y el Plan Curricular del Instituto Cervantes (PCIC), en lo que se refiere concretamente a EL/E, dejó secuelas en el panorama alemán pero fueron principalmente los primeros resultados del informe PISA (2000) lo que produjo en Alemania un schock considerable. Hasta los 90, la preocupación de las instituciones alemanas tenía una orientación hacia el input, es decir, el desarrollo y evaluación detallada del currículum, como así también la redacción de guías didácticas para una enseñanza efectiva. PISA demostró que el rendimiento no cumplía con las expectativas. La Comisión permanente de los Ministerios de Educación y Cultura Federales (KMK) toman medidas, una de las cuales son los NES (Los estándares Nacionales de Educación) que se aplican a todas las asignaturas incluida la primera y segunda lengua extranjera (inglés y francés). Se crea el Instituto para garantizar la calidad de la enseñanza (IQB) que es la institución cuyo objetivo consiste en operacionalizar las competencias en ejemplos concretos de tareas e ítems que, a su vez, se reúnen en tests estandarizados de competencias y en módulos de competencia para la enseñanza. El siguiente cuadro resume las tendencias actuales: 


\begin{tabular}{|c|c|}
\hline + Destrezas & + Competencias \\
\hline + Las destrezas eran cuatro & + Las destrezas son seis \\
\hline $\begin{array}{l}\text { - Las destrezas eran receptivas y produc- } \\
\text { tivas }\end{array}$ & + Todas las destrezas son productivas \\
\hline $\begin{array}{l}\text { + Saber una lengua era la suma de las des- } \\
\text { trezas }\end{array}$ & + Hoy hablamos de competencias parciales \\
\hline $\begin{array}{l}\text { El objetivo final: competencia cercana al } \\
\text { del hablante nativo ideal }\end{array}$ & + Hablantes interculturales \\
\hline $\begin{array}{l}\text { + El objetivo de la clase: práctica y auto- } \\
\text { matización }\end{array}$ & $\begin{array}{l}\text { - El objetivo de la clase: desarrollar com- } \\
\text { petencias cercanas a un uso real }\end{array}$ \\
\hline + Fin $\leftleftarrows$ comprobar conocimientos & + Fin: desarrollar estrategias transferibles \\
\hline $\begin{array}{l}\text { + Tendencia a medir todos los conoci- } \\
\text { mientos funcionales y pragmáticos }\end{array}$ & $\begin{array}{l}\text { + Tareas de diagnóstico, de aprendizaje y } \\
\text { de evaluación }\end{array}$ \\
\hline + Ejercicios y actividades & + Tareas \\
\hline $\begin{array}{l}\text { +El aprendizaje giraba en torno al sistema } \\
\text { lingüístico y es la base de la progresión. }\end{array}$ & $\begin{array}{l}\text { - Ahora tienen la función de instrumentos } \\
\text { para la comunicación, es decir una función } \\
\text { auxiliar y en ese sentido la progresión es } \\
\text { más complicada }\end{array}$ \\
\hline
\end{tabular}

\section{Breve estado de la cuestión}

\subsection{Las estrategias en las publicaciones}

Sin lugar a dudas, el MCER provocó un nuevo interés en el aprendizaje estratégico, pero la historia de la didáctica de las lenguas extranjeras lleva casi cuatro décadas de investigación en este campo. Desde el año 1975, en que Joan Rubin y Hans H. Stern introducen la teoría del buen aprendiz (The Good Language Learner), pasando por Rebecca Oxford y su canon de estrategias y las investigaciones realizadas (Griffiths 2004), hasta llegar a la relación directa entre estrategias y autonomía (Wenden 1991), las publicaciones arrecian. Un buen resumen del estado de la cuestión lo encontramos en Cohen y Macaro (2000), sin olvidar a Anne Uhl Chamot de la universidad de Georgetown (Washington) y sus ingentes investigaciones (ver bibliografía de Francisca Suau Jiménez o el artículo de Sarah Jane Hill, más reciente).

En alemán, la bibliografía también es abundante. Los nombres más conocidos son indudablemente el de Ute Rampillon, Peter Bimmel, Günther Zimmermann y Dieter Wolff, entre muchos otros. 
El libro pionero que incluye las estrategias como parte del programa de aprendizaje ha cumplido ya 23 años. Se trata de Learning to Learn English. A Course in Learner Training (1989). Basta mirar el índice para comprender que aborda cuestiones clave: ¿Qué se espera de un curso? ¿Qué tipo de aprendiz es usted? ¿Para qué quiere usted aprender inglés? ¿Cómo organiza usted el aprendizaje? ¿Cómo va la motivación? ¿Qué tareas puede realizar en el Centro de Autoaprendizaje? Esto, seguido de una serie de actividades relacionadas con las destrezas tradicionales, la gramática y el vocabulario, más un apéndice de formularios que contienen cuestionarios y gráficas sobre estilos de aprendizaje, motivación, objetivos a corto plazo, etc. El objetivo del libro consiste por un lado en optimizar el proceso de aprendizaje y, por otro, instar al estudiantado a asumir más responsabilidad en el mismo.

Un buen resumen de las investigaciones hasta la publicación del Vademécum lo ofrece Sonsoles Fernández (2004: 423-424). Para los manuales que incluyen estrategias, recomiendo la lectura de la tesis de Susana Martín Leralta (2007) y no sólo para eso, ya que constituye una buena discusión del estado de la cuestión y un trabajo pionero en la investigación de estrategias y comprensión auditiva en castellano.

El PCIC, en el apartado 13 (Procedimientos de aprendizaje) propone también un inventario con ejemplos de aplicación. Ambas propuestas son, lógicamente, muy generales. De hilar más fino, deberíamos relacionarlas en primer lugar con las competencias y estas con las destrezas, recurriendo así al capítulo del MCER ( 4.4 y 4.5), que presenta un inventario de actividades y los descriptores correspondientes. Y para concretar aún más, observar el repertorio de técnicas y estrategias pensadas para los ámbitos universitarios (Leder et alii 2005), basada en Profile «Deutsche» (Glaboniat 2002)

El MCER define las estrategias ( 4.4 y 5.1.4) como

Las estrategias son un medio que utiliza un usuario de la lengua para movilizar y equilibrar recursos, poner en funcionamiento destrezas y conocimientos con el fin de satisfacer las demandas de la comunicación que hay en el contexto y completar con éxito la tarea en cuestión de la forma más completa o económica posible, dependiendo de su finalidad concreta. Por lo tanto no habría que ver las estrategias de comunicación simplemente de una perspectiva de incapacidad, como una forma de compensar una carencia o una mala comunicación. El uso de estrategias de comunicación se puede considerar como la aplicación de los principios metacognitivos: planear, ejecutar, controlar y reparar de los distintos tipos de actividad comunicativa: la comprensión, la expresión, la interacción y la mediación. 
El MCER no inventa nada: Estos temas ya son una constante en los estudios de interlengua (Vázquez 1991; Manchón 1993; Baralo 1994; Fernández 1997).

El concepto de estrategia se entiende, en un sentido amplio de la palabra, como toda acción consciente (lingüística, metodológica, cognitiva o metacognitiva) que nos permite alcanzar un objetivo predeterminado. En palabras del MCER, las estrategias se conciben como una bisagra que une las competencias con lo que se puede hacer con ellas (actividades comunicativas). En el capítulo cuatro, se describen sus principios:

a) planificar la acción

b) equilibrar los recursos y compensar las carencias durante la realización

c) controlar los resultados y corregir cuando sea necesario.

\subsection{Las estrategias en la investigación}

\subsubsection{La terminología}

En la bibliografía revisada, la terminología utilizada es variada. En nuestros trabajos decidimos utilizar las siguientes: hablamos de estrategias en el sentido de operaciones mentales conscientes e inconscientes destinadas a cumplir un objetivo de aprendizaje. Adoptamos la siguiente clasificación, que refleja las investigaciones de Rebecca Oxford (1990) y Annita Wenden (1991), en Sonsoles Fernández (2004) (anexo 1).

Las técnicas se refieren a suboperaciones o habilidades que permiten implementar una estrategia (Ejemplo, MCER, p.86). La aplicación reiterada de un comportamiento estratégico determina un determinado estilo de aprendizaje. «Los trucos y pistas» se relacionan con la intervención en el proceso de aprendizaje y suelen aparecer en los manuales como apoyos. El siguiente diagrama resume lo que acabamos de afirmar. ${ }^{2}$

\footnotetext{
2. En el anexo 2 se ofrece una tabla de estrategias y técnicas (productivas y receptivas) que constituye una buena base para incluirlas en el currículum E/LE universitario (Leder et alii, basada en Profile «Deutsch» (Glaboniat 2002). El anexo 3 presenta un resumen de las estrategias de aprendizaje tal cual aparecen en «Con dinámica. Competencias y estrategias».
} 


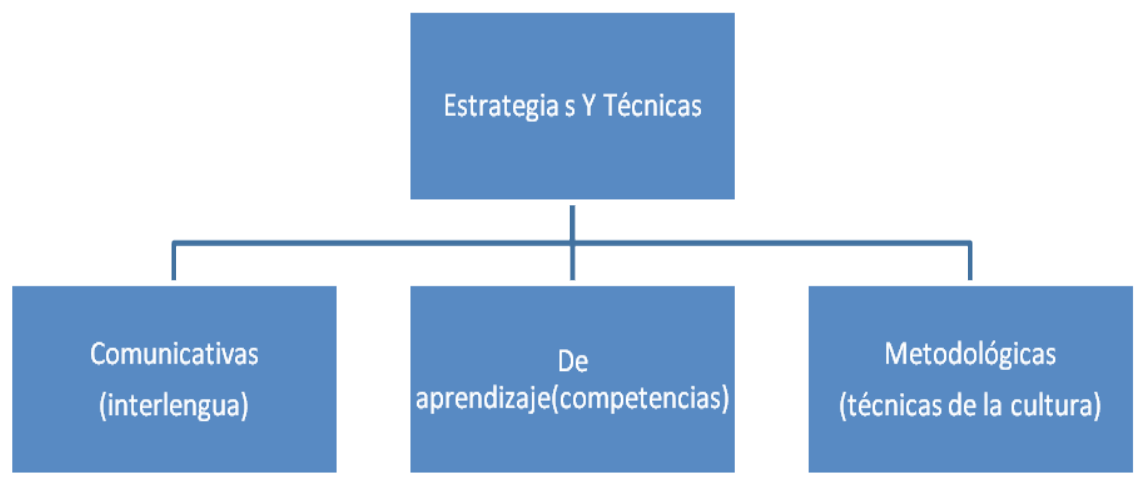

\subsubsection{Estrategias y variables}

- Existe una relación proporcional entre «conocimiento básico sobre el proceso de aprendizaje y sobre la naturaleza del lenguaje» (Wenden 1991 y Ellis 1997) y «una relación directa entre la capacidad cognitiva de los aprendices y la cantidad y complejidad de las estrategias que usan» (Wenden 1991) (citadas por Martín Leralta 2004). Esto no sólo podría poner en tela de juicio la fiabilidad de los cuestionarios que se aplican sino que asimismo demostraría que no hay una relación decisiva entre dominio de la lengua y la frecuencia de estrategias aplicadas.

- Estudiantes de nivel avanzado dicen utilizar más estrategias metacognitivas, por lo cual se concluye que hay una relación proporcional entre el éxito del aprendizaje y el control que se ejerce sobre el mismo (O’Malley et alii 1985a, 1985b).

- Estrategias de tipo cognitivo, tales como identificar estructuras recurrentes o leer por placer, guardan una relación positiva con el éxito del aprendizaje (Ehrman and Oxford 1995).

- Estudiantes de nivel avanzado utilizan todo el repertorio posible de estrategias y aunque la aplicación de las estrategias básicas puede ser altamente productiva no hay prueba suficiente de que, en sí mismas, sean la variable que determine el progreso automático de niveles bajos a niveles altos de proficiencia. (Green y Oxford 1995).

- Existe una correlación positiva entre el nivel del curso y el uso frecuente de estrategias: en los niveles avanzados se utilizan más estrategias que en los niveles bajos, especialmente en lo que se refiere a la interacción en clase, el aprendizaje de vocabulario, la comprensión lectora, la tolerancia a la ambigüedad, el manejo de recursos disponibles, la comprensión del sistema lin- 
güístico, la administración del aprendizaje y el modo de controlar con los sentimientos (Griffiths 2003).

- La observación de las estrategias utilizadas por los así llamados buenos aprendices de lenguas es un proceso eficaz. Sin embargo, no resulta menos interesante observar el fenómeno contrario, es decir, el de las personas con menores niveles de éxito. En este sentido, la dificultad consiste en pedir al estudiantado que cambie las estrategias que les resultan familiares por otras (Sinclair Bell 1995) (O’Malley 1987). Algo similar prueban las investigaciones de Porte (1988). Sus estudiantes afirman haber utilizado estrategias iguales o similares a las que habían utilizado en la escuela de sus países de origen, estrategias que coinciden, y esto es lo interesante, con las que se observan en estudiantes de bajo rendimiento. La diferencia no radica tanto en el tipo de estrategia, sino más bien en la falta de sofisticación y respuesta adecuada a un tipo de actividad en particular.

- No se observan diferencias de género en el uso de estrategias, pero las mujeres tienden a utilizar más estrategias sociales que los varones, siendo la excepción algunas publicaciones con investigaciones realizadas en ciertos países, como Turquía (Oxford 1996).

- La motivación es de lejos la variable más influyente en la utilización de estrategias, como por ejemplo, cuando el aprendizaje tiene una meta clara (relacionado con una carrera) (Ehrman y Oxford 1990).

- El estudiantado europeo utiliza estrategias con más frecuencia que otras nacionalidades, especialmente en lo que se refiere a la interacción en clase, el aprendizaje de vocabulario, la comprensión lectora y la tolerancia a la ambigüedad. En general, el estudiantado europeo alcanza niveles más altos, en el mismo tiempo, que estudiantes de otras nacionalidades (Griffiths y Parr 2000).

En resumen, la edad, la motivación, el nivel y las tradiciones académicas guardan una relación importante en cuanto al tipo y frecuencia de aplicación de estrategias. Por otro lado, no resulta menos importante revisar el aparato de investigación que subyace a las investigaciones y sobre todo su incorporación a los manuales. Como afirma Joseba Ezeiza Ramos, parece imprescindible «crear una plataforma que permita centralizar o, al menos, volcar y hacer valer los trabajos realizados hasta la fecha y que dinamice y coordine las iniciativas que puedan ponerse en marcha en el futuro» (Ezeiza 2010). Este razonamiento, si bien es lógico, podría aplicarse a cualquier parcela de la investigación en E/LE. En nuestro campo, existe una rica tradición de materiales didácticos que tomaron la delantera a la teoría: quienes tengan memoria histórica recordarán que cuando 
se publicaron «Intercambio» (1988) y «Esto funciona» (1990), no había para el español repertorios nocio-funcionales. Peter Slagter acababa de traducir al español el Nivel Umbral. Repito: es el estado de cosas y no necesariamente sinónimo de aconsejable. En cuanto a buscar un denominador común en lo que se refiere a herramientas de investigación, coherencia en la terminología, fiabilidad y validez del aparato estadístico, novedad en el planteamiento de la cuestión a investigar, entre otros factores, no cabe duda que mejoraría notablemente el estado de las cosas, especialmente nos pondría a salvo del peligro de investigar sobre lo que ya sabemos. Asimismo, resulta pertinente la observación de Susana Martín Leralta (2010).

Si revisamos las aportaciones de la bibliografía precedente en cuanto a la relación entre nivel de dominio lingüístico y uso de estrategias, Skehan (1989) afirma que las estrategias no determinan el nivel de dominio de la lengua, sino que son permitidas por él, es decir, que en distintos estadios de conocimiento lingüístico se ponen en práctica estrategias diferentes, y que los alumnos que mayor número emplean no son necesariamente los que mejor dominan el idioma. Igualmente, el estudio de Martín (2009) revela que no hay una relación directa entre el dominio lingüístico y la conciencia de uso de las estrategias, puesto que algunos sujetos con alta competencia en el uso de la LE no son capaces de identificar las estrategias que emplean, mientras que otros aprendices menos eficaces sí reconocen conscientemente las estrategias que aplican a la resolución de las tareas.

Todo lo anterior permite afirmar que al igual que las personas nativas no siempre están en condiciones de dar cuenta de la gramaticalidad, aceptabilidad y adecuación de sus propias producciones, del mismo modo hablantes de E/LE que detentan una alta capacidad lingüística, pragmática, intercultural y metodológica hacen uso inconsciente de las estrategias. Dudo, a través de la propia experiencia en cursos de habilidades académicas, que puestas a interrogar a dichas personas a través de la técnica thinking aloud protocols estén en condiciones de verbalizar los procesos que los han conducido a la producción. Sin embargo, esto plantearía una cuestión interesante relacionada con la teoría conocida como The good language learner.

\section{La visibilización de las estrategias en los manuales}

La introducción de las estrategias en los manuales es un buen ejemplo de intervención docente en los procesos de aprendizaje de lengua, en el sentido - no paradójico- de autonomía dirigida. El manual, como guión, presenta un canon de 
estrategias que si bien pueden formar parte de acervo de aprendizaje no resultan obvias para la totalidad del estudiantado

Para ello, las personas que enseñamos debemos tener un conocimiento teórico de las estrategias, pero al mismo tiempo, para que ese conocimiento teórico se haga concreto en tareas, hay que diseñarlas, explicitar las estrategias y hacer uso de ellas de manera continua y repetida en clase, tanto en la práctica guiada como en situaciones de trabajo autónomo. Es decir: concebimos la enseñanza en situaciones formales, como un proceso dirigido que debe y puede influir el proceso de aprendizaje a través de:

1. La integración de estrategias (meta) cognitivas, sociales, afectivas y de compensación a los conocimientos lingüísticos y tareas

2. Un traspaso paulatino pero constante de la responsabilidad docente al estudiantado.

Utilizando la metáfora del andamio, lo que hacemos primero es proporcionar el andamiaje y lo vamos retirando de a poco, a medida que aumenta el dominio de la lengua.

Compartimos la convicción de que es aconsejable, útil y eficaz incluir una reflexión de las estrategias en la práctica cotidiana. Retomando las palabras de Nunan (1995), «la clase de lengua tiene un doble foco: enseñar contenidos y concientizar acerca de los procesos de aprendizaje». Para ello, la nueva generación de manuales y su aplicación debe garantizar la presentación explícita, su uso recurrente, reflexión sobre la utilidad, y la corrección si procede. El resultado predecible: actuación independiente en contextos imprevisibles. La fórmula que sigue representa los elementos y su interrelación:

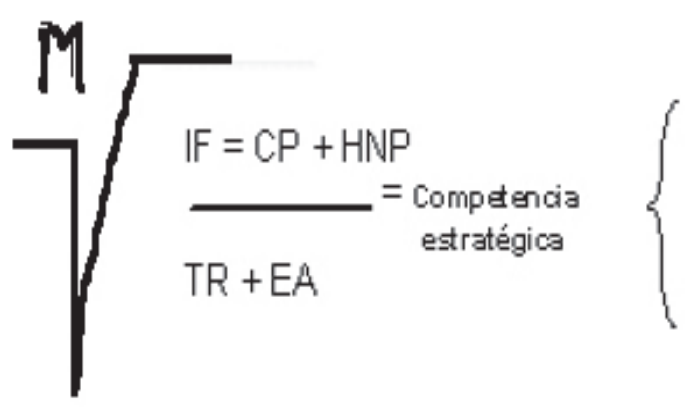

Estudiar de maner a eficaz Aprender a aprender Autonomía Formación a lo lago de lavida

La competencia estratégica es el resultado de la integración de las estrategias en la instrucción. La instrucción formal = clases presenciales + horas no presenciales divididas por el tiempo real disponible + los estilos de aprendizaje individuales. Todo bajo el signo de la motivación, que es el verdadero motor del 
aprendizaje. En otras palabras, la competencia estratégica, como parte de la competencia comunicativa, relaciona los conocimientos con la acción y la persona. Es una onda expansiva que alcanza y dinamiza el proceso de aprender, es la bisagra que une el saber con saber hacer.

\section{Aspectos menos positivos y malentendidos}

Planteamos a continuación, de manera esquemática, las voces que ponen en tela de juicio los planteamientos mencionados anteriormente:

- Si además de explicar y practicar todo lo que hay en el libro, me tengo que poner a enseñar a aprender, no hay tiempo que alcance.

Respuesta: se invierte primero para ganar tiempo después. Es una inversión a largo plazo. Si en la escuela, en la clase de lengua materna, historia, geografía y biología se empezara desde el comienzo a utilizar estrategias, al llegar a la primera, segunda o tercera lengua extranjera, podríamos prescindir de ellas en la universidad. Lógicamente esto, mal hecho, puede llevar al problema que mencionaré a continuación. El mayor peligro al que nos enfrentamos cuando hablamos de introducir estrategias explícitas consiste en ir en contra de hábitos adquiridos. $\mathrm{Si}$ pretendemos introducir redes y mapas mentales para retener y reutilizar léxico y venimos de la tradición del Vokabelheft, tenemos un problema. Si venimos de la tradición de lo que en alemán se llama Berichtigung, la corrección explícita, mucho trabajo tendremos si esperamos que el estudiantado acepte la doble corrección con comentarios o la simple fotocopia que entregamos tras haber escrito un texto para que se corrija en casa y se compare con la corrección de la profesora o profesor la clase siguiente. Si no logramos transmitir claramente que una cosa es aprender a usar el diccionario y otra consultar constantemente el diccionario, lógicamente nos daremos contra un muro de rechazo. Si estos procedimientos simples no forman desde el comienzo de la instrucción formal parte de la rutina del curso, habremos perdido en muchos casos la batalla.

- El aprendizaje estratégico contradice la noción de autonomía. Si tomamos la autonomía al pie de la letra no hay que enseñar estrategias.

Respuesta: De la misma manera que no hay que confundir libertad con libertinaje, no hay que confundir autonomía con prácticas autodidactas; no hay que confundir cambio de papel en el profesorado con prescindencia de la persona docente, principio doblemente peligroso en los tiempos que corren.

- El aprendizaje estratégico contradice la noción de aprendizaje cooperativo.

Respuesta: nada indica que pudiera existir tal contradicción, todo lo contrario. Se pueden adoptar estrategias válidas de otras personas. Esto se lleva a cabo en clase, 
pidiendo que las personas expliquen en voz alta cómo han resuelto un problema. Por otro lado varias estrategias de carácter social o afectivo, como aprender en grupo o parejas o pedir ayuda y colaboración son perfectamente comparables a otras estrategias metacognitivas.

- Las estrategias y la autonomía no pertenecen al ámbito de la clase.

Respuesta: la clase es el ámbito ideal para practicar lo que se aplicará después, en situaciones no controladas. Por otro lado, la autonomía es un concepto complejo que depende de la edad y de las tareas que realizan las personas que aprenden. Por otro lado, los cambios sociales del último decenio, formulados desde el mundo del trabajo y de la economía para la formación de adultos, adhiere al postulado de la formación permanente. En ese sentido la autonomía es la capacidad de tomar decisiones y asumir responsabilidades. La autonomía también presupone el principio de diferenciación, que permite tener en cuenta diversas motivaciones y necesidades en el alumnado.

- Las estrategias no son directamente observables. La competencia estratégica sólo puede evaluarse indirectamente a través de tareas. Y llevando la discusión a un extremo: ¿realizar con éxito esas tareas, no prueba solamente eso? ¿Cómo generalizar a contextos de otro tipo no controlables?

Respuesta: existen técnicas de elicitación (Oxford 1990 y Chamot 1999).

\subsection{Aspectos positivos de las estrategias}

- Eficacia: las personas que disponen de un amplio repertorio de estrategias pueden controlar mejor su propio proceso de aprendizaje. No sólo tienen claros los objetivos sino que saben cómo lograrlos de manera efectiva.

- Motivación y autoconfianzał la aplicación de las estrategias lleva al aumento de la motivación, lo cual hace que las personas que aprenden se involucren con los procesos lingüísticos. Si tienen a mano recursos para superar problemas, ganan en confianza frente a las dificultades.

- Independencia: quien aprende a aplicar estrategias depende menos de la persona que enseña y está mejor pertrechada para enfrentar situaciones imprevisibles.

+ Autonomía: puede seguir por su cuenta con el aprendizaje.

- Transferencia a otros campos de aprendizaje o a otras lenguas afines.

- Relación de las estrategias y las competencias. 
En el nivel existencial («saber ser y estar») se encontraría todo lo relativo a la personalidad del estudiante, su perfil socio-afectivo y su capacidad de aprendizaje. + Otros de los componentes del mapa se situarían en el nivel operativo («saber hacer»). En este nivel se encontrarían las actitudes con las que el estudiante se aproxima al aprendizaje de la lengua meta (y el comportamiento con el que se materializan dichas actitudes), los factores que configuran el entorno de aprendizaje (qué tipo de «acciones» se ejecutan para aprender la lengua) y las estrategias que despliega con dicho fin. + El tercer bloque de factores se relacionaría con lo que podríamos denominar «saber acerca de». En este nivel se concentrarían los factores que definen el perfil sociodemográfico del estudiante (conocimientos y experiencias previas que constituyen el bagaje personal del individuo), los factores motivacionales (las razones y objetivos que mueven al individuo a estudiar la lengua) y los factores relacionados con su aptitud lingüística (las lenguas que conoce y el nivel de competencia alcanzado en cada una de ellas $y$, en especial, en la lengua meta). (Ezeiza 2010)

\section{Conclusiones y perspectivas}

Este trabajo pretende dar un somero panorama de la investigación en torno a las estrategias y ejemplos de práctica en cuanto a su inclusión en manuales y currículos (véanse anexos 1 y 2). La bibliografía presentada da cuenta de lo hecho y servirá a las futuras generaciones para plantearse cuestiones didácticas y de investigación.

El camino abierto por la literatura anglosajona y alemana ya ha dado frutos en el campo E/LE pero todavía se echan de menos investigaciones relacionadas con el ámbito de las competencias y las destrezas, especialmente la mediación, la comprensión audiovisual y la interacción oral. La implementación de las TICs y la comunicación virtual también plantea nuevos desafíos en el campo académico y laboral.

Ámbitos tales como la enseñanza de lenguas a inmigrantes y los tan mentados programas bilingües y multilingües podrán encontrar un buen aliado en el desarrollo del componente estratégico.

Es de esperar que el público lector de estas páginas encuentre en ellas algunos impulsos para sus futuros trabajos y algunos apoyos que faciliten la labor cotidiana. 


\section{Referencias bibliográficas ${ }^{3}$}

Baralo, M. (1995). Errores y fosilización. Madrid. Colección Aula de español. Fundación Antonio de Nebrija.

Benson, P. University of Hong Kong. [Disponible en: <http://www.learningpaths.org/bibliographies/bibliographies/bibliographies.html>].

Bernardo Carrasco, J. (2007). Estrategias de aprendizaje. Para aprender más y mejor, Madrid, Ediciones Rialp [Disponible en: <http://marcoele.com/descargas/11/sanchez-estrategias-ludico.pdf $>$ ].

Bimmel, P. y Rampillon, U. (2001). Lernerautonomie und Lernstrategien, Berlin, Langenscheidt.

Cohen, A. y Macaro, E. (2007). Language Learner Strategies: 30 years of Research and Practice. Oxford. Oxford University Press.

Снамот, A. et alii (1999). The Learning Strategies Handbook. White Plains. NY. Addison Wesley Longman.

Снамот, A. et alii (2004). Issues in Language Learning Strategy Research and Teaching. [Disponible en: <http://e-flt.nus.edu.sg/v1n12004/chamot.htm>].

Díez, M.; Fernández, R. y Halbach, A. (2004). Debate en torno a las estrategias de aprendizaje / Debating Learning Strategies. Frankfurt am Main. Peter Lang.

Ecknardt, P. Lern- und Arbeitstechniken des Fremdsprachenunterrichts für den bilingualen Sachfachunterricht [Disponible en: <http://www.abc.brandenburg. de/docs/eckhard.pdf $>$ ].

Ellis, G. y Sinclair, B. (1989). Learning to learn English. A course in learning training. Cambridge. Cambridge University Press.

Ellis, R. (1997). Second Language Acquisition. Oxford. Oxford University Press.

Ehrman, M. y Oxford, R. (1990). «Adult language learning styles and strategies in an intensive training setting». The Modern Language Journal, 74 (3): 311-327.

- (1995). «Cognition plus: correlates of languagenl earning success». The Modern Language Journal, 79 (1): 67-89.

Ezeiza, J. (2010). «Hacia un Marco para situar al alumno como centro del proceso de enseñanza/aprendizaje Bases teóricas, metodológicas y estructurales». Revista Nebrija de Lingüistica Aplicada, 8 (4): 78- 87.

3. Todos los enlaces se comprobaron (10-04-2012). 
FERnández, S. (1997). Interlengua y análisis de errores en el aprendizaje del espanol como lengua extranjera. Madrid. Edelsa.

- (2004a). «La subcompetencia estratégica». En: Sánchez Lobato, J. y SANtos Gargallo, I. (eds.). Vademécum para la formación de profesores. Enseñar español como segunda lengua (L2) y lengua extranjera (LE). Madrid. SGEL: 573-592.

- (2004b). «Las estrategias de aprendizaje». En* Sánchez Lobato, J. y SANtos Gargallo, I. (eds.). Vademécum para la formación de profesores. Enseñar español como segunda lengua (L2) y lengua extranjera (LE). Madrid. SGEL: 411-433.

García Salinas, J. y Ferreira Cabrera, A. (2010). «Entrenamiento en estrategias de aprendizaje de inglés como lengua extranjera en un contexto de aprendizaje combinado». Revista Nebrija de Lingüística Aplicada, 8 (4): 17-40.

Glaboniat, M.; Müller, M.; Rusch, P; Schmitz, H.; Wertenschlag, L. (2002). Profile Deutsch. A1-B2. Version 1.0, Berlin, München, Wien, Zürich, New York, Langenscheidt.

Green, J.; Oxford, M. \& R. (1995). «A closer look at learning strategies, L2 Proficiency and Gender». TESOL Quarterly, 29/2: 261-297.

Griffiths, C. (2003). Language learning strategies, use and proficiency. The relationship between patterns of reported language learning strategy (LLS) use by speakers of other languages (SOL) and proficiency with implications for the teaching/learning situation [Disponible en: <https://researchspace.auckland. ac.nz/bitstream/handle/2292/9/02whole.pdf?sequence $=6>$ ].

- (2004). «Language Learning Strategies: Theory and Research». School of Foundations Studies AIS. St Helens, Auckland, New Zealand. Occasional Paper No. 1 [Disponible en: <http://www.crie.org.nz/research_paper/c_griffiths_ op1.pdf> ].

Griffiths, C. y PArr, J. (2000). «Language learning Strategies, nationality, independence and proficiency». Independence, 28: 7-10.

Hill, S. J. (2004). «La falta de un consenso en la definición de una estrategia de aprendizaje». En: Díez, M.; Fernández, R. y Halbach, A. Debate en torno a las estrategias de aprendizaje / Debating Learning Strategies. Frankfurt am Main. Peter Lang* 21-26.

Косн, C. (2011). «Strategienः Spanisch effektiver lernen und anwenden». Der fremdsprachliche Unterricht Spanisch, 35: 4-11.

Leder et alii (2005). Documento interno del Centro de Lenguas de la FFU Berlin. 
Manchón, R. (1993). «La evaluación del componente estratégico del aprendizaje de lenguas». En: Miquel, L. y Sanz, N. (eds.). Didáctica del español como lengua extranjera. Madrid. Fundación Actilibri.

MAREP (2007). Marco de referencia para los enfoques plurales de las lenguas y las culturas. Consejo de Europa [Disponible en: <http://carap.ecml.at/LinkClick.aspx?fileticket $=2 \mathrm{~h} 4 \mathrm{E} 794 \mathrm{AZ}$ Z8 $=\&$ tabid $=425 \&$ language $=\mathrm{en}-\mathrm{GB}>$ ] .

Martín Leralta, S. (2004). «Tausche DaF gegen Sonne - Die deutsche Sprache im heutigen Spanien». Der interkulturelle Kontext in der professionellen Bildung und internationalen Kommunikation. Internationale Konferenz. 15-17 September 2004. Nowgorod (Rusia).

- (2008). Orientaciones para la inclusión de las estrategias en el programa habitual de ELE [Disponible en: <http://marcoele.com/orientaciones-para-la-inclusion-de-las-estrategias-en-el-programa-habitual-de-ele/> ].

- (2009). Competencia estratégica para la comprensión auditiva en español como lengua extranjera. Colección de Monografías ASELE, 12. Madrid. Ministerio de Educación.

- (2010)+ «Comentarios al artículo: La mujer y las estrategias de aprendizaje en la adquisición de la lengua inglesa». Revista Nebrija de Lingüística Aplicada, 8 (4) $\div 78-87$.

Monereo, C. (coord.) (2009). Estrategias de enseñanza y aprendizaje. Barcelona. Graó [Disponible en: <http://www.terras.edu.ar/jornadas/79/ biblio/79Analisis-de-los-factores.pdf $>$ ].

Moreno Valdés, M. T. (1995). Estrategias de aprendizaje. Camaguey. Centro de Estudios de Ciencias de la Educación. [Disponible en: <http://ftp.ceces.upr. edu.cu/centro/repositorio/Textuales/Libros/PsE/Estrategias_de_aprendizaje.pdf $>$ ].

Naiman, N.; Frohlich, M.; Stern, H. H. y Tedesco, A. (1978). «The good language learner». Research in Education Series, 7. Toronto. The Ontario Institute for Studies in Education [Disponible en: <http //leap.tki.org.nz/supporting_language_development/goals/extending_students_existing_learning_strategies $>$ ].

Norton, B. y Toohey, K. (2001)+ «Changing Perspectives on Good Language Learning». TESOL Quarterly, 35, (2)ः 307-322.

NunAN, D. (1995). «Learner strategy training in the classroom: A case study». (Comunicación personal- Documento no publicado). 
O’Malley, J. M.; Chamot, A.; Stewner-Manzanares, G.; Kupper, L.; Russo, R. (1985a). «Learning strategies used by beginning and intermediate ESL students». Language Learning, 35/1:21-46.

- (1985b). «Learning strategy applications with students of English as a second language». TESOL Quarterly 19(3): 557-584.

O’Malley, J. M.; Снамот, A. U. (1990). Learning strategies in second language acquisition. Cambridge. Cambridge University Press [Disponible en: <http:// homepage.ntlworld.com/vivian.c/SLA/L2_learning_strategies.htm > ]

Oxford, R. L. (1990). Language learning strategies: what every teacher should know. Boston. Heinle\&Heinle Publishers.

- (1990). Strategy Inventory for Language Learners [Disponible en: <http:// www2.education.ualberta.ca/staff/olenka.Bilash/best\%20of\%20bilash/ SILL\%20survey.pdf $>$ ].

- (ed.). (1996). Language Learning Strategies around the Word: Cross-cultural perspectivas. USA. University of Hawaii Press.

Porte, G. (1988). «Poor language learners and their strategies for dealing with new vocabulary». ELT Journal, 42/3: 167-171.

Pozo Minucio, J. I. (s. f.). Adquisición de estrategias de aprendizaje. [Disponible en: <http://www.educadormarista.com/descognitivo/APESTRAT. HTM>].

Rampillon, U. y Zimmermann, G. (1997). Strategien und Techniken bim Erwerb fremder Sprachen. Ismaning. Hueber.

Ríos Santana, H. (2007-2009). «Estrategias de aprendizaje y autonomía en los manuales aula». Redele [Disponible en: <http //www.educacion. gob.es/dctm/redele/Material-RedEle/Biblioteca/2011_BV_12/2011_ BV_12_17Rios.pdf?documentId=0901e72b80e18e0b>].

Rodríguez Rodríguez, M. (coord.). (2004). Estrategias en el aprendizaje de E/ LE. Cuadernos de Didáctica E/LE. Revista Forma, 7. Madrid. SGEL.

Rubin, J. (1975). «What the 'good language learner' can teach us». TESOL Quarterly, 9: 41-51.

Sánchez Benítez, G. (2010). «Las estrategias de aprendizaje a través del elemento lúdico». Marco ELE [Disponible en: <http //marcoele.com/descargas/11/sanchez-estrategias-ludico.pdf $>$ ].

Sinclair Bell, J. (1995). «The relationship between L1 and L2 literacy: Some complicating factors». TESOL Quarterly, 29/4: 687-704. 
Skeman, P. (1989). Individual differences in second language learning. London. Edward Ardnold.

Stern, H. H. (1975). «What can we learn from the good language learner?». Canadian Modern Language Review, 34, 304-318.

Suau Jiménez, F. (2000). La inferencia léxica como estrategia cognitiva. Aplicación al discurso escrito en lengua inglesa. Quaderns de Filologia. Universitat de València. Anejo n. ${ }^{\circ}$ XXXVII .

Wenden, A. L. (1991). Learner strategies for learner autonomy. United Kingdom. Prentice Hall.

Wolff, D. (s. f.). Lernstrategien: ein Weg zu mehr Lernerautonomie. [Disponible en: <http://paedpsych,jk.uni-linz.ac.at:4711/LEHRTEXTE/Wolff98.html> ].

ZHANG, L. J. (s. f.). Making a case for skills/strategies-based instruction for L2 listening development. National Institute of Education. Nanyang Technological University* [Disponible en: <http //www.nus.edu.sg/celc/publications/ RELT72/119to128zhang.pdf $>$ ].

Vázquez, G. E. (1991). Análisis de errores y aprendizaje de español / lengua extranjera. Frankfurt am Main. Peter Lang.

- (1998). ¿Errores? ¡Sin falta! Madrid. Edelsa.

VV. AA (2007). Español lengua viva. Madrid. Santillana E/LE.

VV. AA (2009). Con dinámica. Competencias y estrategias. Stuttgart. Klett.

VV. AA (2009). Con dinámica. En autonomía. Stuttgart. Klett.

VV. AA (2011). Viá rápida. Barcelona. Difusión.

VV.AA (2012). Vía rápida. Cuaderno de ejercicios. Barcelona. Difusión.

VV. AA (2011). Plan curricular del Instituto Cervantes [Disponible en: <http:// www.cervantes.es/lengua_y_ensenanza/aprender_espanol/plan_curricular_instituto_cervantes,htm $>$ ]. 


\section{Anexos}

\section{Anexo 1}

Estrategias de aprendizaje directas

1. De memoria

+ Crear asociaciones mentales (agrupar, relacionar con lo conocido, contextualizar).

- Asociar con imágenes y sonidos (dibujos, mapas semánticos, palabras claves, palabras fonéticamente próximas).

- Repasar.

- Actuar (respuesta física, seguir órdenes).

2. Cognitivas

+ Practicar (repetir, práctica formal, reconocer y usar estructuras y modelos, ensayar, práctica natural).

- Recibir y enviar mensajes (sacar la idea principal, utilizar recursos variados para comunicar).

- Analizar y razonar (aplicar reglas y conocimientos a nuevas situaciones, analizar expresiones y sus elementos, contrastar lenguas, traducir, transferir).

- Inventar recursos para organizar la información recibida y poder reutilizarla (tomar notas, resumir, subrayar, evidenciar).

3. Compensatorias

- Adivinar el sentido (a partir de claves lingüísticas o extralingüísticas).

- Superar carencias (cambiar de lengua, pedir ayuda, utilizar gestos, abandonar la comunicación, seleccionar el tema, alterar el mensaje y ajustarlo a lo que se conoce, inventar palabras, utilizar sinónimos o perífrasis).

- Estrategias de aprendizaje indirectas.

4. Metacognitivas

- Enfocar y delimitar lo que se va a aprender (visión de conjunto, inserción en lo conocido, centrar la atención, dar prioridad a la comprensión).

- Ordenar y planear (explicitar cómo se aprende, organizar el estudio, formular los objetivos - también de las tareas-, planear lo necesario para ejecutar una tarea, buscar oportunidades para practicar).

- Evaluar el aprendizaje (controlar los propios problemas, buscar soluciones y evaluar el progreso).

5. Afectivas

- Reducir la ansiedad (técnicas de relajación).

- Animarse (pensar en los propios aspectos positivos, arriesgarse con prudencia, recompensarse). 
- Controlar las emociones (escuchar al propio cuerpo, hacer tests para conocerse, escribir un diario sobre la propia motivación en el aprendizaje, hablar con otras personas sobre los sentimientos y actitudes en el aprendizaje).

6. Sociales

- Pedir aclaraciones, verificaciones o correcciones.

- Interactuar con las personas de la clase o fuera de ella con personas nativas. Empatizar con otras personas (intentar comprender la cultura, los pensamientos y sentimientos).

(Fernández 2004: 423-424) 


\section{Anexo 2}

\begin{tabular}{|c|c|}
\hline \multicolumn{2}{|l|}{ PLANIFICAR } \\
\hline ESTRATEGIA & TÉCNICA \\
\hline $\begin{array}{l}\text { 1. Activar conocimientos } \\
\text { previos. }\end{array}$ & $\begin{array}{l}\text { - Controlar lo que se sabe sobre un tema (R). } \\
\text { - Informarse sobre la existencia de diagramas, } \\
\text { apoyos visuales, dibujos (R). } \\
\text { - Controlar las fuentes (R). }\end{array}$ \\
\hline $\begin{array}{l}\text { 2. Activar y diagramar } \\
\text { estructuras textuales. }\end{array}$ & $\begin{array}{l}\text { - Reconocer las palabras claves en las partes de un } \\
\text { texto }(\mathrm{P} / \mathrm{R}) \text {. } \\
\text { - Utilizar modelos existentes }(\mathrm{P}) \text {. } \\
\text { - Diferenciar entre lengua escrita y lengua oral (P). } \\
\text { - Recordar diferentes géneros textuales }(\mathrm{P}) \text {. }\end{array}$ \\
\hline $\begin{array}{l}\text { 3. Tomar consciencia de } \\
\text { los intereses propios y } \\
\text { ajenos. }\end{array}$ & $\begin{array}{l}\text { - Ser consciente de lo que puede o no interesar a } \\
\text { otras personas }(\mathrm{P}) \text {. } \\
\text { - Ser consciente hasta qué punto se quiere exponer } \\
\text { o escribir en detalle }(\mathrm{P}) \text {. } \\
\text { - Ser consciente de qué y de cuánto se quiere com- } \\
\text { prender. }(\mathrm{P} / \mathrm{R}) \text {. }\end{array}$ \\
\hline 4. Prever dificultades. & $\begin{array}{l}\text { - Prepararse ante la dificultad que pueda presentar } \\
\text { un texto incompleto o ambiguo (R). } \\
\text { - Reconocer variedades, registros, jergas (R). } \\
\text { - Tener en cuenta el registro de un texto (R). } \\
\text { - Tener en cuenta los turnos de palabra (R/P). }\end{array}$ \\
\hline $\begin{array}{l}\text { 5. Adaptar la tarea a las } \\
\text { competencias personales } \\
\text { y lingüísticas en una } \\
\text { situación concreta. }\end{array}$ & $\begin{array}{l}\text { - Enfocar un tema }(\mathrm{P}) \text {. } \\
\text { - Decidir qué género textual se va a utilizar }(\mathrm{P}) \text {. } \\
\text { - Decidir cómo expresar lo fundamental a través de } \\
\text { los recursos lingüísticos disponibles }(\mathrm{P}) \text {. } \\
\text { - Administrar el tiempo a disposición }(\mathrm{P} / \mathrm{R}) \text {. }\end{array}$ \\
\hline 6. Repetir y practicar & $\begin{array}{l}\text { - Practicar nuevas estructuras y sus combinaciones, } \\
\text { utilizarlas y pedir una reacción (P.) }\end{array}$ \\
\hline
\end{tabular}




\begin{tabular}{|c|c|}
\hline $\begin{array}{l}\text { 7. Buscar apoyos e infor- } \\
\text { maciones }\end{array}$ & $\begin{array}{l}\text { - Reflexionar sobre el vocabulario específico }(\mathrm{P}) \text {. } \\
\text { - Ordenar el contenido de un texto por criterios de } \\
\text { importancia }(\mathrm{P}) \text {. } \\
\text { - Confeccionar listas de vocabulario específico }(\mathrm{P}) \text {. } \\
\text { - Completar notas }(\mathrm{P} / \mathrm{R}) \text {. } \\
\text { - Subrayar palabras y estructuras clave }(\mathrm{R}) \text {. } \\
\text { - Practicar transiciones textuales }(\mathrm{P}) \text {. }\end{array}$ \\
\hline \multicolumn{2}{|c|}{ EJECUTAR, CONTROLAR, REPARAR } \\
\hline $\begin{array}{l}\text { 1. Apoyarse en cono- } \\
\text { cimientos previos. }\end{array}$ & $\begin{array}{l}\text { - Buscar palabras y expresiones conocidas }(\mathrm{P}) \text {. } \\
\text { - Aplicar reglas conocidas }(\mathrm{R}) \text {. } \\
\text { - Comparar lo leído y escuchado con los conoci- } \\
\text { mientos propios }(\mathrm{R}) \text {. }\end{array}$ \\
\hline $\begin{array}{l}\text { 2. Captar implicaciones } \\
\text { inferir. }\end{array}$ & $\begin{array}{l}\text { - Prestar atención al lenguaje no verbal (R). } \\
\text { - Prestar atención a los recursos temáticos (R). } \\
\text { - Inferir el significado a través del contexto (R). } \\
\text { - Inferir el significado a través de otras lenguas (R). } \\
\text { - Inferir el significado a través de la composición de } \\
\text { palabras (R). } \\
\text { - Reconocer la función de los marcadores textuales } \\
\text { (R). }\end{array}$ \\
\hline $\begin{array}{l}\text { 3. Controlar la compren- } \\
\text { sión. }\end{array}$ & $\begin{array}{l}\text { - Confirmar la comprensión }(\mathrm{P}) \text {. } \\
\text { - Volver a leer partes de un texto }(\mathrm{R}) \text {. } \\
\text { - Repetir lo comprendido }(\mathrm{P}) \text {. } \\
\text { - Pedir aclaraciones }(\mathrm{P}) \text {. } \\
\text { - Pedir confirmación si algo es correcto o no }(\mathrm{P}) \text {. }\end{array}$ \\
\hline $\begin{array}{l}\text { 4. Sacar conclusiones e } \\
\text { inferir. }\end{array}$ & $\begin{array}{l}\text { - A partir de señales lingüísticas y el contexto, iden- } \\
\text { tificar la intención y prever lo que vendrá (P). } \\
\text { - Formular hipótesis sobre el tema a través de ele- } \\
\text { mentos gráficos, fotos e ilustraciones }(\mathrm{R}) \text {. } \\
\text { - Formular hipótesis sobre el tema a través de ele- } \\
\text { mentos para lingüísticos y paratextuales (R). } \\
\text { - Inferir lo desconocido a través del conocimiento } \\
\text { del mundo y la propia experiencia (R). } \\
\text { - Adivinar lo que sigue (R). } \\
\text { - Clasificar textos, según el género y las característi- } \\
\text { cas retóricas }(\mathrm{R}) \text {. }\end{array}$ \\
\hline
\end{tabular}




\begin{tabular}{|c|c|}
\hline $\begin{array}{l}\text { 5. Estructuras textos y } \\
\text { contenidos. }\end{array}$ & $\begin{array}{l}\text { - Estructurar un texto en partes y encontrar un tí- } \\
\text { tulo }(\mathrm{P}) \text {. } \\
\text { - Hacer un esquema del texto. }(\mathrm{P}) \text {. } \\
\text { - Utilizar gráficos e ilustraciones para comprender } \\
(\mathrm{R}) \text {. } \\
\text { - Utilizar técnicas de visualización }(\mathrm{P}) \text {. } \\
\text { - Identificar señales argumentativas }(\mathrm{R} / \mathrm{P}) \text {. }\end{array}$ \\
\hline $\begin{array}{l}\text { 6. Interpretar textos y } \\
\text { reconocer puntos de } \\
\text { vista. }\end{array}$ & $\begin{array}{l}\text { - Expresar una opinión frente a un texto (acuerdo / } \\
\text { desacuerdo) }(\mathrm{P}) \text {. } \\
\text { - Extrapolar informaciones importantes }(\mathrm{P}) \text {. } \\
\text { - Reconocer argumentos }(\mathrm{P}) \text {. } \\
\text { - Sacar conclusiones que no necesariamente se rela- } \\
\text { cionan con el texto (P). } \\
\text { - Establecer relaciones con otros textos y otras } \\
\text { fuentes }(\mathrm{P}) \text {. } \\
\text { - Reconocer usos idiomáticos y metafóricos (R). } \\
\text { - Reconocer juegos de palabras, ambigüedades y } \\
\text { connotaciones (R). } \\
\text { - Comprender un amplio espectro de léxico acadé- } \\
\text { mico en contexto (R). }\end{array}$ \\
\hline $\begin{array}{l}\text { 7. Estructurar la conver- } \\
\text { sación. }\end{array}$ & $\begin{array}{l}\text { - Formular afirmaciones como preguntas y vicever- } \\
\text { sa }(\mathrm{P}) \text {. } \\
\text { - Tomar la palabra }(\mathrm{P}) \text {. } \\
\text { - Mantener la palabra a través de recursos adecua- } \\
\text { dos }(\mathrm{P}) \text {. } \\
\text { - Dirigirse a la interlocutora o interlocutor }(\mathrm{P}) \text {. } \\
\text { - Poner fin a una conversación }(\mathrm{P}) \text {. } \\
\text { - Reducir la redundancia o utilizarla correctamente. } \\
(\mathrm{P}) \text {. } \\
\text { - Introducir, con corrección, consenso, objeción, } \\
\text { desacuerdo, objeciones, etc. }(\mathrm{P}) \text {. }\end{array}$ \\
\hline
\end{tabular}




\begin{tabular}{|l|l|}
\hline 8. Controlar. & - Controlar hipótesis y expectativas (R). \\
-Escucharse a sí misma/-o (R). \\
- Volver a leer o escuchar textos desde otra pers- \\
pectiva (R). \\
-Corregir textos desde el punto de vista gramatical \\
(P). \\
- Evaluar la propia actuación a partir de listas de \\
chequeo (P). \\
\hline - Revisar hipótesis. \\
- Aclarar malentendidos. \\
- Recomenzar frases. \\
- Reformular frases. \\
- Disculparse. \\
- Pedir que se repita algo. \\
- Verbalizar una suposición o sospecha no dicha. \\
- Desarrollar la capacidad de autocorrección, po- \\
niendo atención sólo en ciertos aspectos. \\
\hline - Poner atención a las palabras acentuadas e inferir \\
a través de ellas el significado de otras palabras (R). \\
- Llevar una conversación hacia un tema conocido \\
(R). \\
- Poner atención a los puntos clave (P/R) \\
- Evitar palabras «difíciles» (P). \\
- Parafrasear conceptos (P). \\
- Utilizar términos genéricos o palabras semántica- \\
mente cercanas (P). \\
- Utilizar estructuras simples (P). \\
- Parafrasear términos desconocidos con palabras \\
desconocidas (P). \\
- Utilizar palabras de otras lenguas, eventualmente \\
con la pronunciación o terminación de la que se está \\
aprendiendo (P). \\
- Citar en lugar de disertar (P).
\end{tabular}




\begin{tabular}{|c|c|}
\hline 11. Cooperar. & $\begin{array}{l}\text { - Involucrar a otras personas en una conversación } \\
\text { (P). } \\
\text { - Referirse a lo dicho por otra persona (P). } \\
\text { - Manejar la cortesía (P). } \\
\text { - Relacionar el discurso propio con el de la interlo- } \\
\text { cutora o interlocutor }(\mathrm{P}) \text {. }\end{array}$ \\
\hline 12. Intentar. & $\begin{array}{l}\text { - Utilizar palabras y estructuras recién aprendidas } \\
\text { (P). } \\
\text { - Intentar reproducir la pronunciación, entonación, } \\
\text { la melodía de la frase, el ritmo propio de la lengua } \\
\text { extranjera }(\mathrm{P}) \text {. } \\
\text { - Utilizar técnicas variadas para ampliar el vocabu- } \\
\text { lario (R). }\end{array}$ \\
\hline $\begin{array}{l}13 \text { Utilizar herramientas } \\
\text { de apoyo. }\end{array}$ & $\begin{array}{l}\text { - Controlar la ortografía con un diccionario: } \\
\text { - Utilizar programas informáticos. } \\
\text { - Calibrar qué palabras son más efectivas al utilizar } \\
\text { buscadores. } \\
\text { - Comprender abreviaturas. } \\
\text { - Reutilizar los propios apuntes y anotaciones. } \\
\text { - Consultar el propio libro de texto y encontrar en } \\
\text { el mismo respuestas y soluciones. } \\
\text { - Utilizar modelos a la hora de escribir. } \\
\text { - Citar correctamente. Evitar el plagio. } \\
\text { - Comprobar la corrección de las fuentes. } \\
\text { - Desarrollar una actitud crítica: no creer ciegamen- } \\
\text { te ni en el diccionario ni en la red. } \\
\text { - Encontrar rápidamente la información que se busca. } \\
\text { - Leer en diagonal. } \\
\text { - Integrar la información encontrada de manera co- } \\
\text { herente: } \\
\text { - Utilizar obras de referencia para producir y mejorar } \\
\text { textos propios y para ampliar la variedad de recursos: } \\
\text { (Glaboniat et alii 2002, adaptado al contexto de la } \\
\text { universidad). }\end{array}$ \\
\hline
\end{tabular}




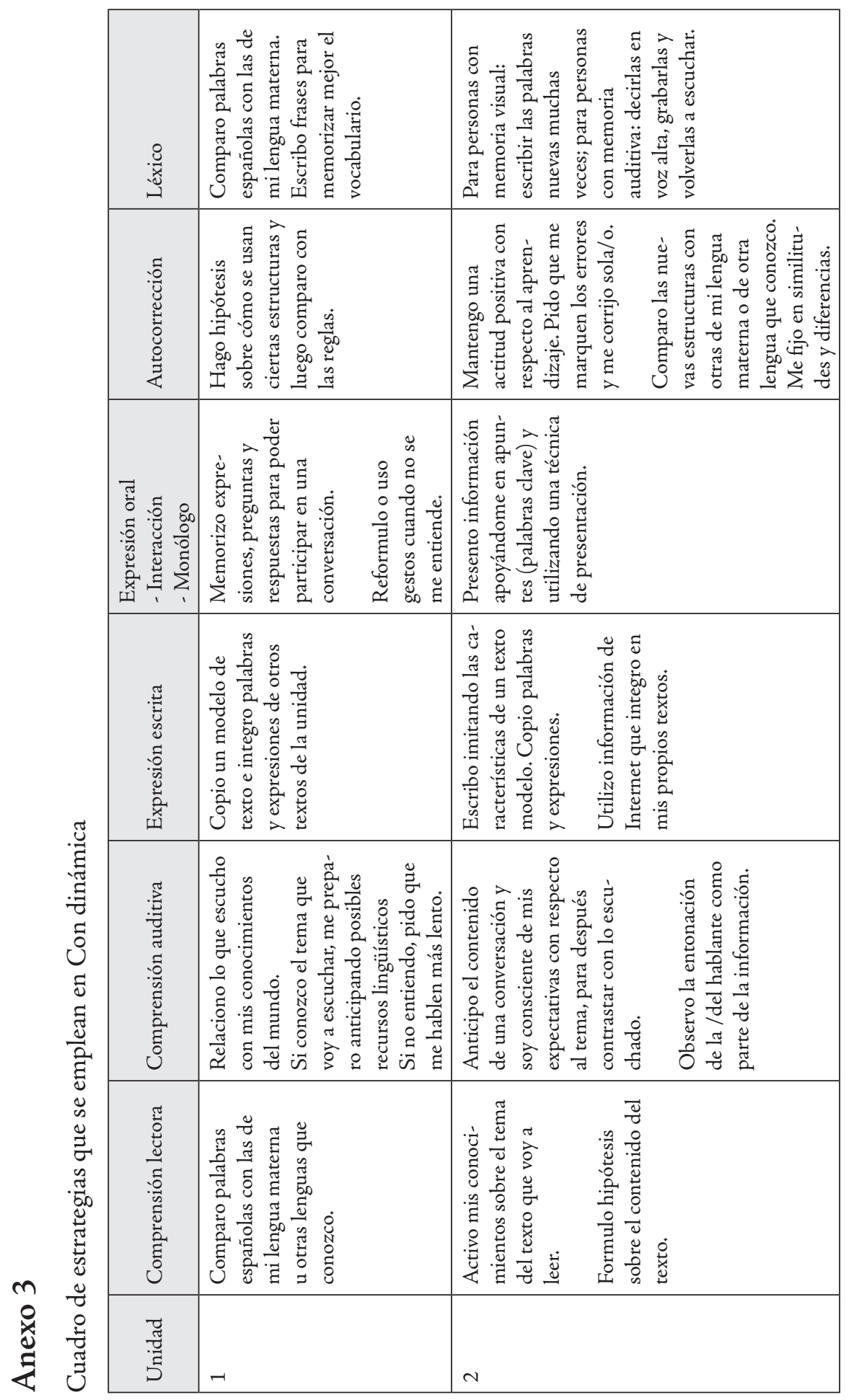




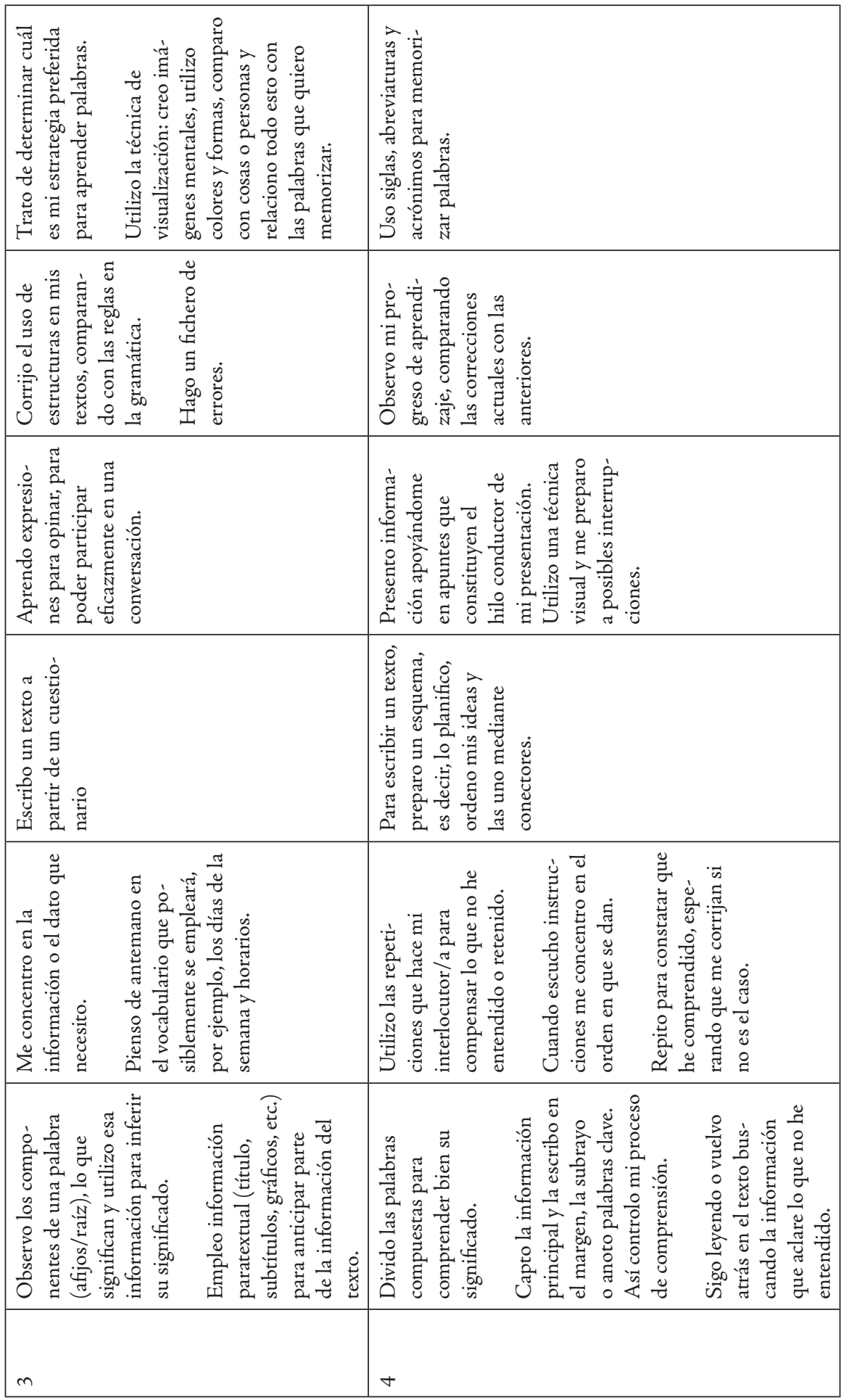




\begin{tabular}{|c|c|}
\hline 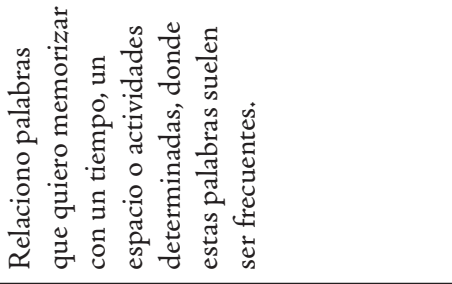 & 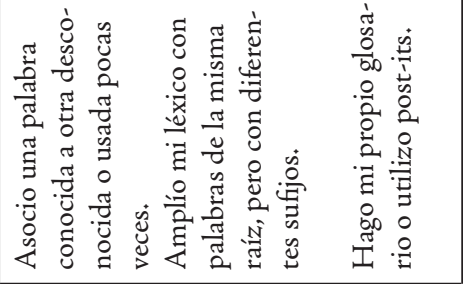 \\
\hline 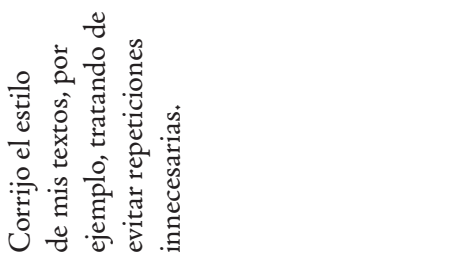 & 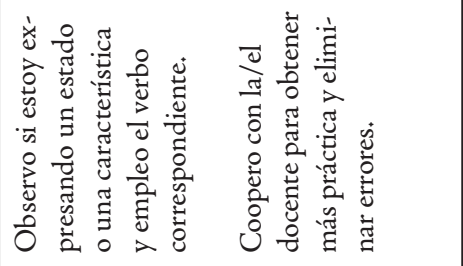 \\
\hline 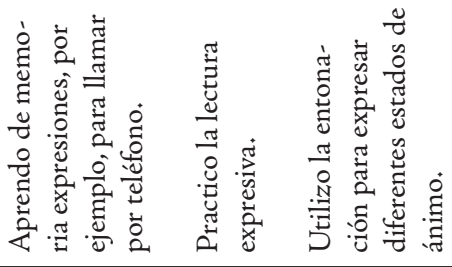 & 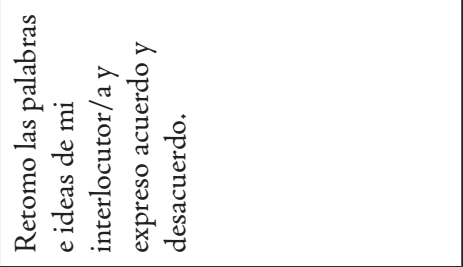 \\
\hline 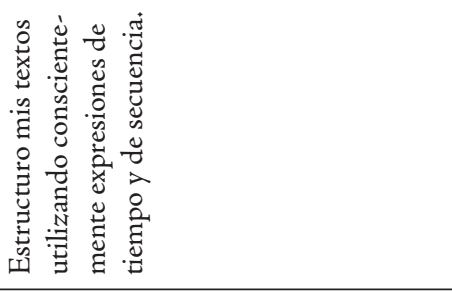 & 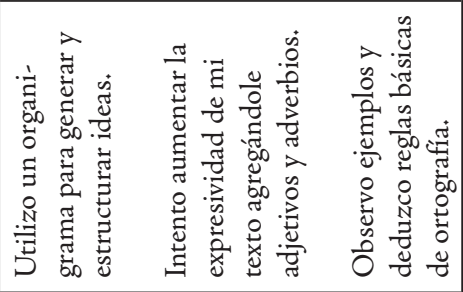 \\
\hline 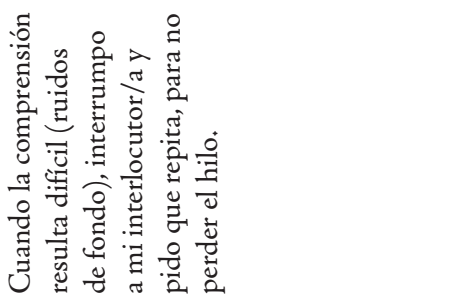 & 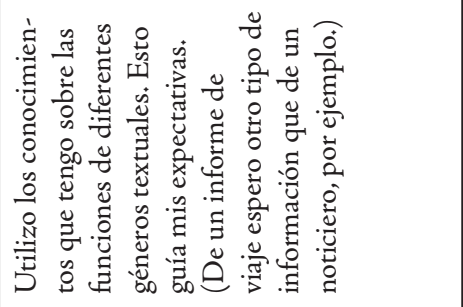 \\
\hline 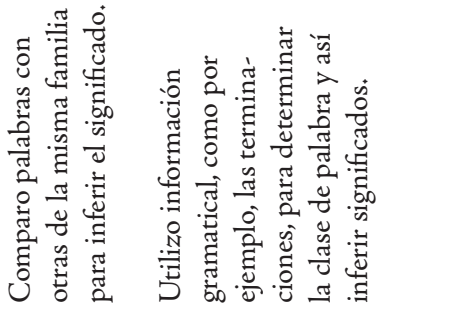 & 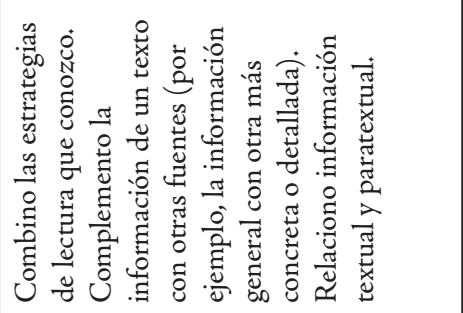 \\
\hline in & \\
\hline
\end{tabular}




\begin{tabular}{|c|c|}
\hline 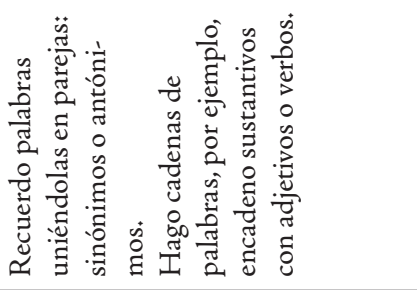 & 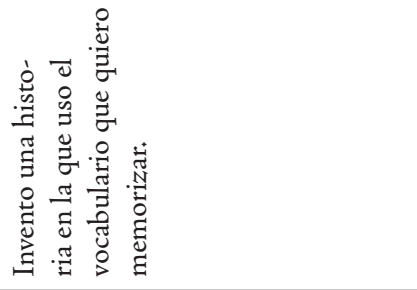 \\
\hline 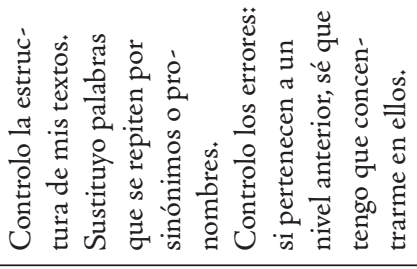 & 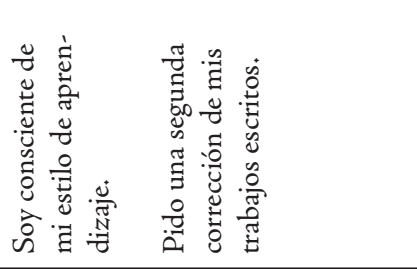 \\
\hline 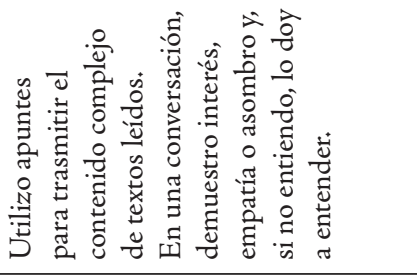 & 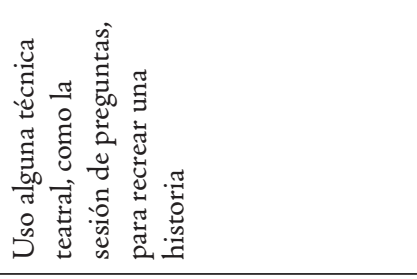 \\
\hline 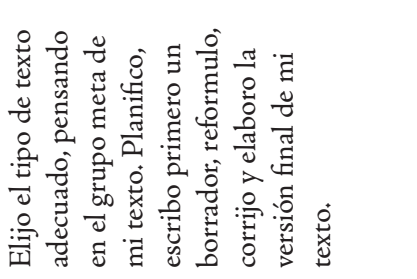 & 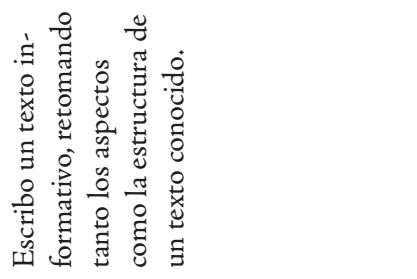 \\
\hline 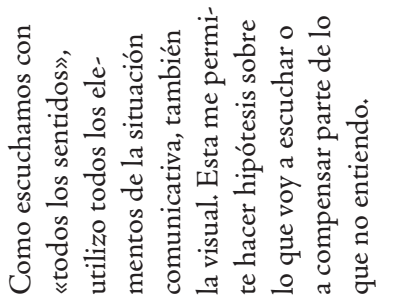 & 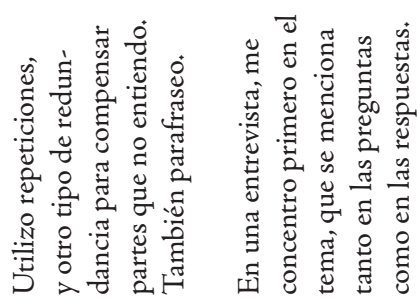 \\
\hline 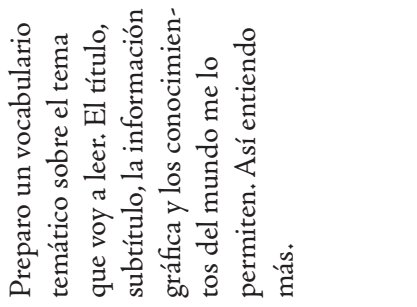 & 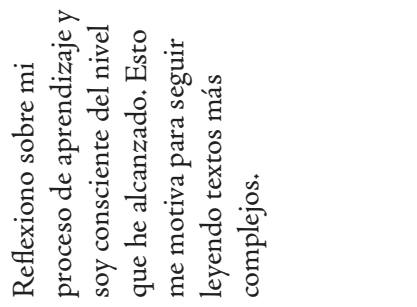 \\
\hline$\Lambda$ & \\
\hline
\end{tabular}




\begin{tabular}{|c|c|c|c|c|}
\hline \multicolumn{2}{|l|}{ 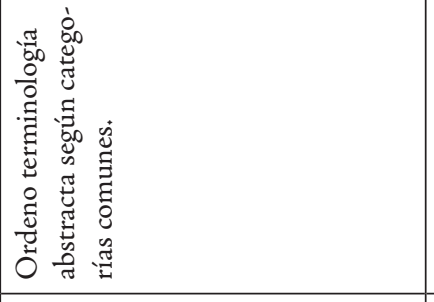 } & \multicolumn{3}{|l|}{ 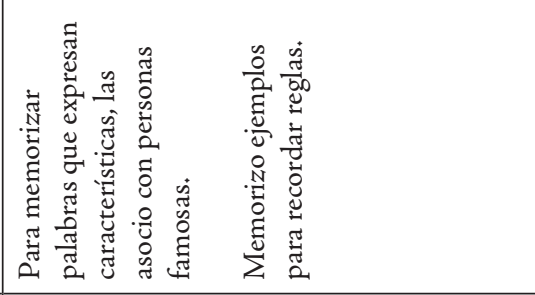 } \\
\hline \multicolumn{2}{|c|}{ 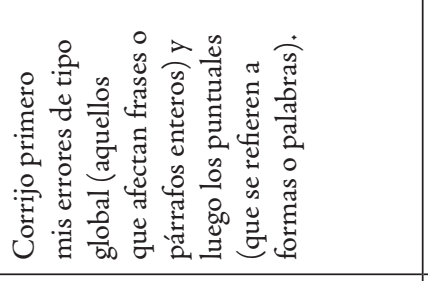 } & \multicolumn{3}{|l|}{ 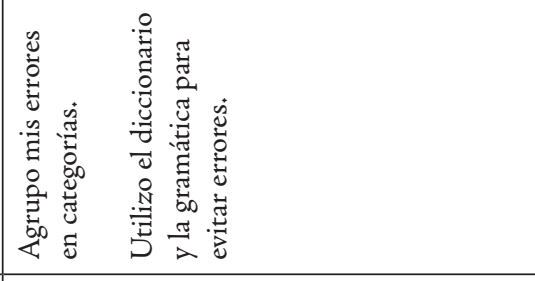 } \\
\hline \multicolumn{2}{|c|}{ 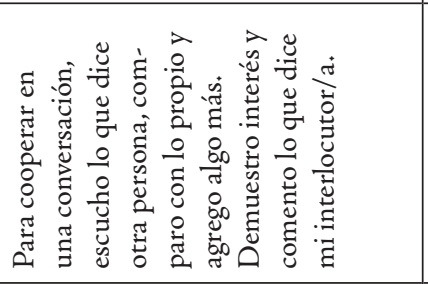 } & \multicolumn{3}{|c|}{ 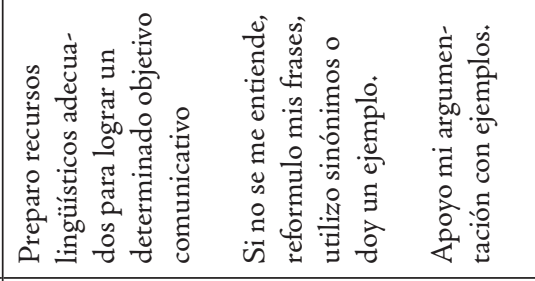 } \\
\hline \multicolumn{2}{|c|}{ 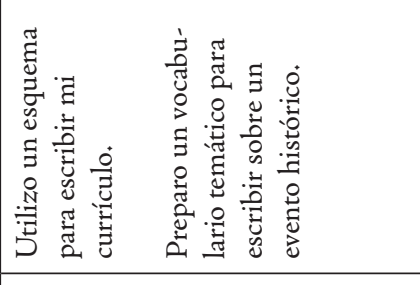 } & \multicolumn{3}{|l|}{ 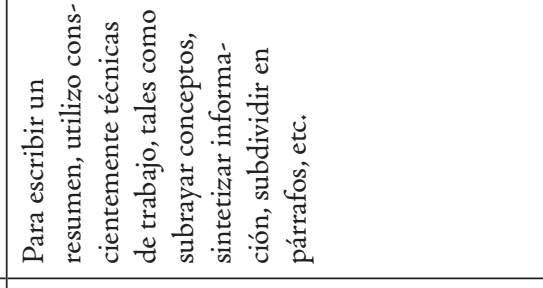 } \\
\hline \multicolumn{2}{|c|}{ 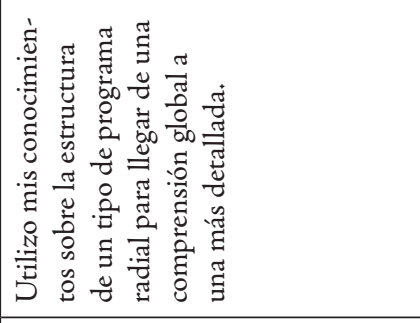 } & 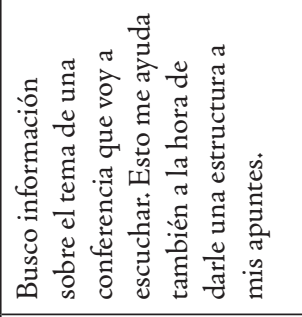 & 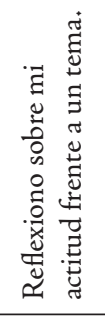 & 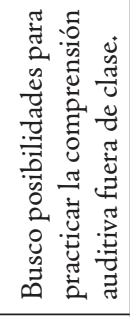 \\
\hline 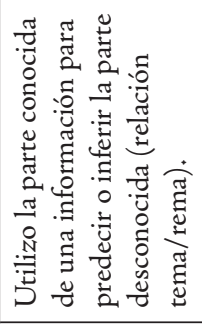 & 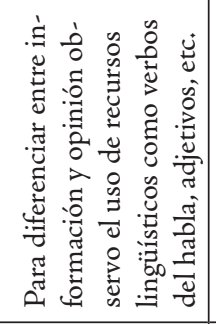 & \multicolumn{3}{|c|}{ 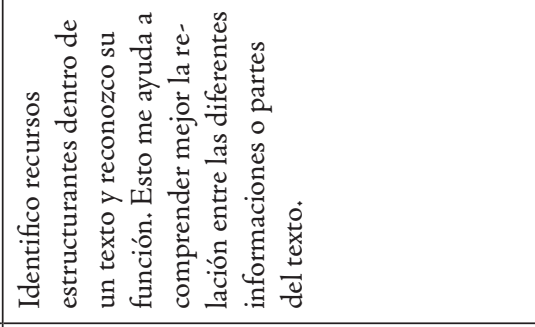 } \\
\hline$a$ & & & & \\
\hline
\end{tabular}


El desarrollo del componente estratégico dentro del marco actual de la didáctica de ELE...

\begin{tabular}{|c|c|}
\hline 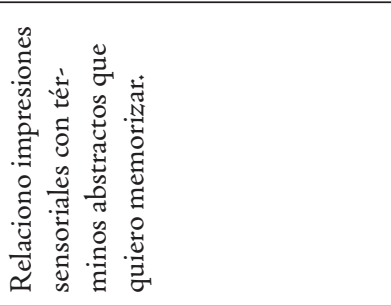 & 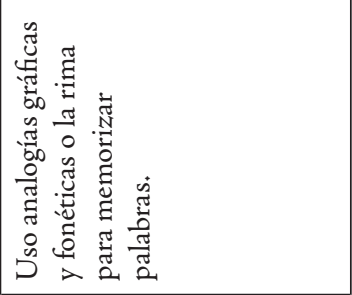 \\
\hline 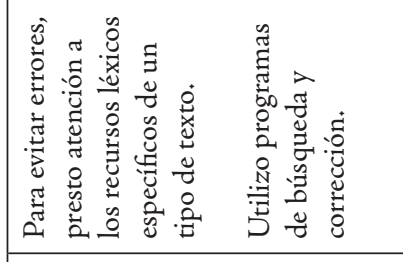 & \\
\hline 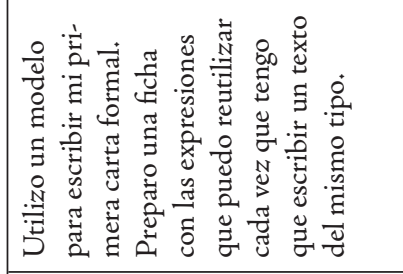 & 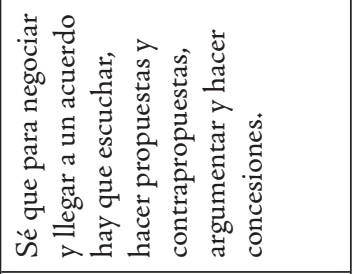 \\
\hline 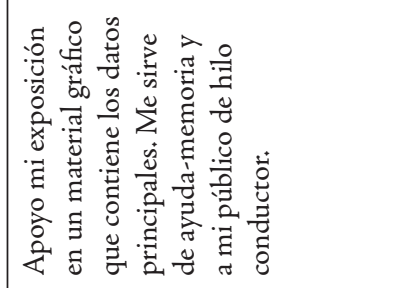 & 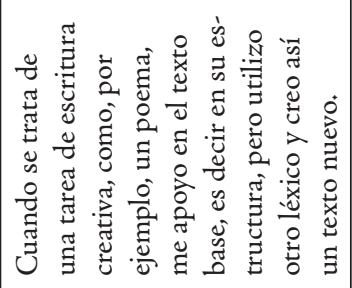 \\
\hline 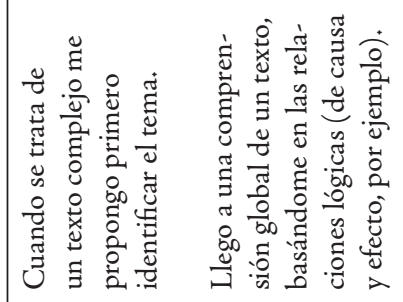 & 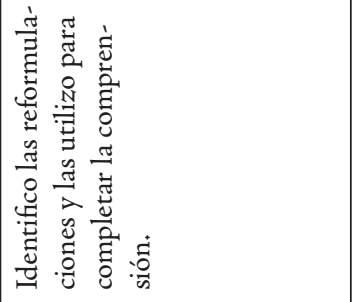 \\
\hline 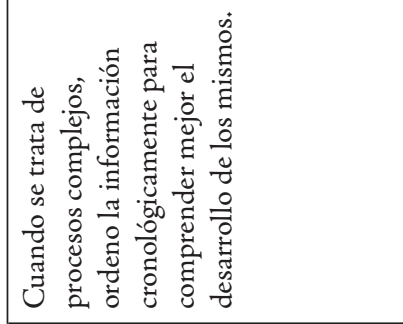 & 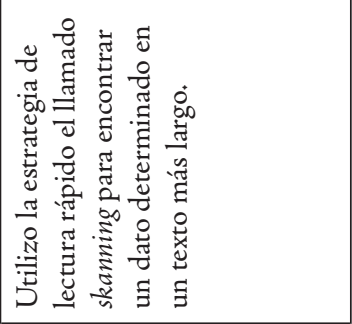 \\
\hline$\exists$ & 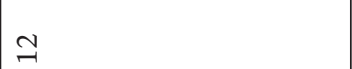 \\
\hline
\end{tabular}




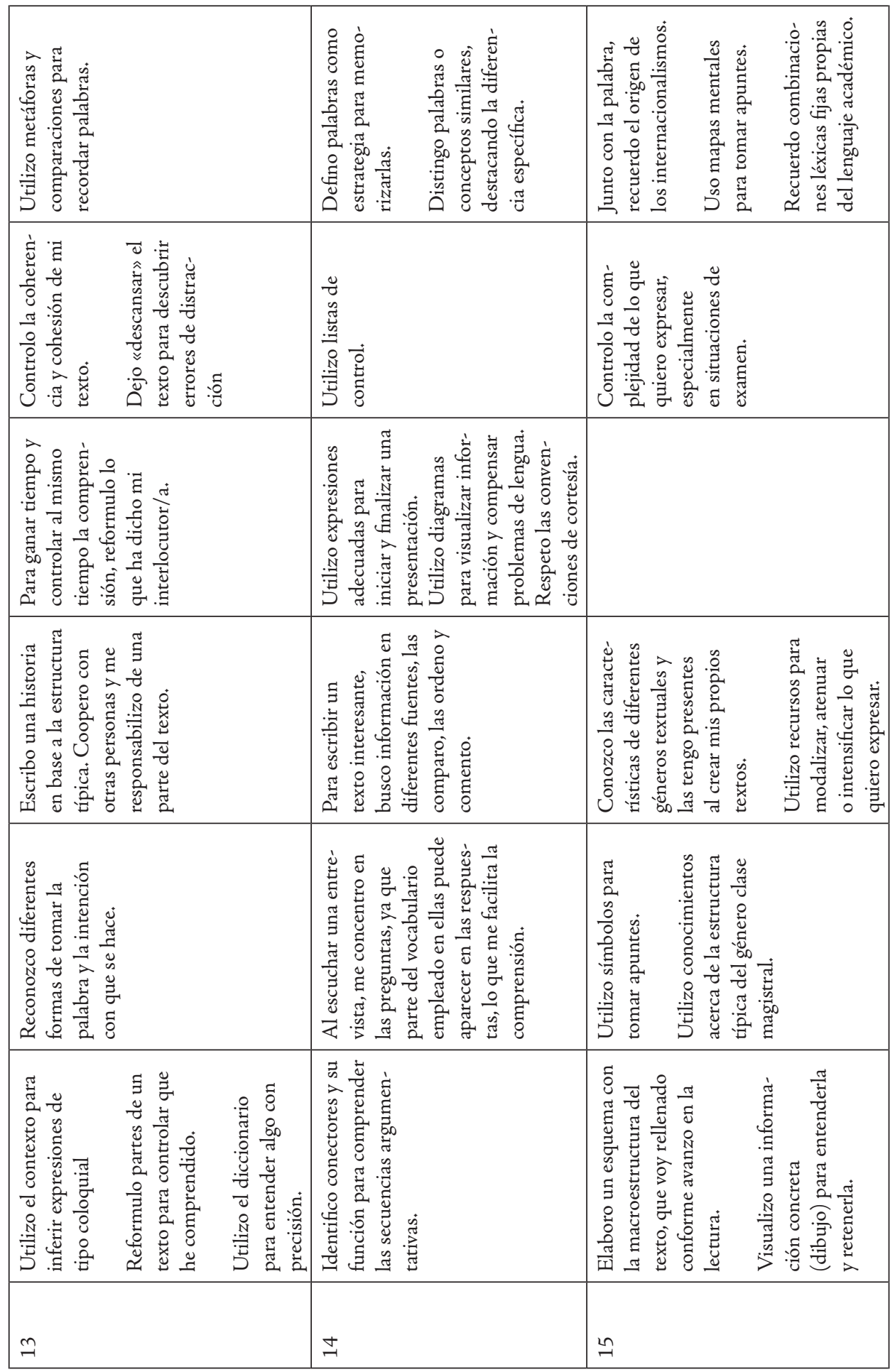

